\title{
ENSINO MÉDIO E AS AÇÕES DE PERMANÊNCIAS NA UNIVERSIDADE: PESQUISAS EM MOVIMENTO
}

\author{
Elizeth Gonzaga dos Santos Lima ${ }^{1}$ \\ https://orcid.org/0000-0002-3340-5587 \\ Jackeline Nascimento Noronha da $\mathrm{Luz}^{2}$ \\ https://orcid.org/0000-0001-5327-9584
}

\begin{abstract}
RESUMO: A relação entre o ensino médio e a universidade se constitui uma importante vertente a ser estudada na atual conjuntura, tendo em vista os processos que os estudantes perpassam até ingressarem na universidade. $O$ objetivo desse artigo é identificar os debates e discussões, sobre as demandas do ensino médio e as ações de permanências instituídas nas universidades. $O$ aporte teórico utiliza-se de referências que discutem ingresso, permanência, democratização, ensino médio, universidade e trajetória. Como procedimentos metodológicos utiliza-se a abordagem qualitativa, a partir de pesquisas bibliográficas em artigos, teses e dissertações. Assim, considera-se que a partir do percurso de mudanças nas políticas de acesso à educação superior, as pesquisas acadêmicas caminharam e desenvolveram análises para compreender tal mudanças e movimento, contribuindo com desvelamentos da realidade e fortalecimento das ações de permanência.
\end{abstract}

PALAVRAS-CHAVE: ensino médio. universidade. ingresso. permanência.

\section{HIGH SCHOOL AND STAY ACTIONS AT THE UNIVERSITY: RESEARCH IN MOTION}

ABSTRACT: The relationship between high school and university is an important aspect to be studied in the current situation, considering the processes that students go through until they enter university. The purpose of this article is to identify the debates and discussions on the demands of high school and the actions of permanence instituted in universities. The theoretical contribution uses references that discuss admission, permanence, democratization, high school, university and trajectory. As methodological procedures, the qualitative approach is used, based on bibliographic research in articles, theses and dissertations. Thus, it is considered that from the

1 Doutora em Educação. Docente permanente do Programa de Pós-Graduação em Educação e do Curso de Pedagogia da UNEMAT. Cáceres, Mato Grosso - Brasil. elizeth@unemat.br

2 Doutora em Educação. Docente e Coordenadora do curso de Pedagogia - UNIVAG. Cuiabá, Mato Grosso - Brasil. Jacke.lux@gmail.com 
course of changes in policies for access to higher education, academic research has moved forward and developed analyzes to understand such changes and movement, contributing to unveiling reality and strengthening permanence actions.

KEYWORDS: high school. university. ticket. permanence.

\section{ACCIONES DE ESCUELA SECUNDARIA Y ESTANCIA EN LA UNIVERSIDAD: INVESTIGACIÓN EN MOVIMIENTO}

RESUMEN: La relación entre la escuela secundaria y la universidad es un aspecto importante a estudiar en la situación actual, en vista de los procesos que atraviesan los estudiantes hasta ingresar a la universidad. El propósito de este artículo es identificar los debates y discusiones sobre las demandas de la escuela secundaria y las acciones de permanencia instituidas en las universidades. La contribución teórica utiliza referencias que discuten admisión, permanencia, democratización, escuela secundaria, universidad y trayectoria. Como procedimientos metodológicos, se utiliza el enfoque cualitativo, basado en la investigación bibliográfica en artículos, tesis y disertaciones. Por lo tanto, se considera que desde el curso de los cambios en las políticas de acceso a la educación superior, la investigación académica ha avanzado y desarrollado análisis para comprender dichos cambios y movimientos, contribuyendo a revelar la realidad y fortalecer las acciones de permanencia.

PALABRAS CLAVE: bachillerato. universidad. boleto. permanencia.

\section{Introdução}

Este artigo tem como objeto a relação ensino médio e universidade, no Brasil. Seu objetivo é identificar os debates e discussões, sobre a relação do ensino médio e as ações de permanências instituídas nas universidades, em publicações acadêmicas divulgadas como teses de doutorado, dissertações de mestrado e artigos. Com base em estudo teórico da categoria democratização do acesso e as discussões de Pierre Bourdieu sobre o meio social, podemos refletir criticamente sobre as produções encontradas no campo das produções acadêmicas-científicas.

A justificativa para a produção deste trabalho insere-se dentro da discussão da democratização do acesso à educação superior brasileira. É relevante ressaltar, que o direito à educação básica tem caráter compulsório, gratuito e, acima de tudo, universal. No caso do Brasil, a Constituição Federal de 1988 assegura, no Artigo 205, que a educação é um direito de todos, dever do Estado 
e da família, e será promovida com a colaboração da sociedade, visando ao desenvolvimento da pessoa, seu preparo para o exercício da cidadania, bem como, a sua qualificação para o trabalho. Se, por um lado, reconhece-se à educação básica como um direito universal, a educação superior é tida como um direito social. Dessa forma, para ingressar na educação superior, o indivíduo deve ter concluído o ensino médio e ter sido aprovado em processos seletivos específicos para o ingresso em determinado estabelecimento de educação superior (ES).

Entretanto, o acesso à educação superior ainda não é universalizado, considerando que as vagas disponibilizadas não atendem à demanda que deseja ingressar. De acordo com parâmetros internacionais para universalizar o acesso a ES, o país precisa ter $30 \%$ dos jovens de 18 a 24 anos na ES, o Brasil em 2019 chegou a 17\%, significa dizer que o Brasil nem atingiu a meta de universalização internacional, ou seja, há um caminho para se construir para que o acesso seja garantido. (SILVA et al, 2018).

Ainda, após o ingresso, a preocupação torna-se com a permanência do estudante na educação superior, e as diversas influências, desde o que antecede ao evento em si, ao que se apresenta no percurso acadêmico e, ainda, ao que se tem como projeção de vida futura. Os antecedentes dizem respeito à trajetória econômica, cultural e de escolaridade do estudante; o percurso acadêmico tem relação com o grau de estímulos ou dificuldades para levar adiante os estudos; as projeções representam o que o acadêmico vislumbra como profissão, diante das condições inscritas socialmente, o que pode se refletir como motivação ou não. Assim, tornando a busca pela compreensão dessa relação da sua trajetória no ensino médio e sua inserção na universidade e o que esta faz para sua permanência, é importante para a compreensão da democratização do acesso.

E neste percurso de mudanças nas políticas de acesso à educação superior, as pesquisas acadêmicas caminharam e desenvolveram análises para compreender tal mudanças e movimentos, contribuindo com desvelamentos da realidade e fortalecimento das ações de permanência.

$\mathrm{O}$ artigo está dividido em três sessões, a primeira trata da democratização: caminhos para o acesso à educação superior; a segunda discute o meio social do estudante: contribuições de Pierre Bourdieu; a terceira apresenta o levantamento da relação ensino médio e universidade nas produções acadêmicas. Posteriormente, as considerações finais.

\section{A democratização: caminhos para o acesso à educação superior}


Compreendemos que a democracia tem um sentido complexo e contraditório, na medida em que vivemos em uma sociedade capitalista, com uma conjuntura excludente e meritocrática. Desse modo, Silva e Veloso (2013, p.413), analisam que:

\begin{abstract}
[...] no pensamento marxista, não existe uma "verdadeira democracia", posto que a mesma consiste, essencialmente, na "luta pela democracia", "jamais completamente vitoriosa, porque, em virtude de suas contradições, a democracia pode sempre avançar e regredir". Portanto, trata-se de uma construção dialética, pautada em momentos de afirmação, de negação e de superação de eventos ou ideias, permanentemente.
\end{abstract}

Provavelmente, essa seja a síntese essencial que apreendemos dos autores: a democracia sob a base material capitalista apenas pode ser admitida, porque assim se faz na realidade, sob o olhar da categoria contradição.

E contradição, cabe aqui uma retomada a ela, se refere a dois contrários em luta, em ação, em movimento, polos que estão em unidade e confronto ao mesmo tempo. Como destaca Cury $(1986$, p. 30) a contradição não é apenas entendida como categoria da interpretação do real, "mas também como sendo ela própria existente no movimento do real, como motor interno do movimento, já que se refere ao curso do desenvolvimento da realidade". A par dessa compreensão, consideramos que a democracia em sua relação com o capitalismo, contraditório, por natureza, somente pode se realizar de forma contraditória.

Sob essa bússola, aproximando-nos de nosso tema de pesquisa, buscamos compreender uma categoria que nos permitisse compreender a realidade que a ele diz respeito. Entendemos que a utilização do termo democratização possibilitaria uma análise mais profícua da realidade, pois possibilita um olhar sobre as políticas educacionais, enquanto processo de uma construção de educação com acesso pleno. Em outras palavras, possibilita verificar se tais políticas, como se apresentam hoje, engendram aspectos que lhe deem um sentido de democracia plena. $O$ que pode ser esclarecido diante da contribuição das autoras Silva e Veloso (2013, p. 6), que concebem a democratização como:

[...] avanços sociais, que podem engendrar mudanças na direção da democracia (em sentido pleno). Sob determinadas condições e motivações, a democratização pode constituir-se em elemento fundamental à construção da democracia, a exemplo de certas iniciativas no campo da educação. Nessa 
linha, a "democratização referenciada na democracia" reporta e se condiciona ao enfrentamento de elementos causais e projeta embates que põem em questão estruturas enraizadas, ou, no limite, a própria ordem social vigente. (SILVA; VELOSO, 2013, p. 6 grifo nosso).

Assim, compartilhamos da ideia de Silva e Veloso (2013), que discutem a categoria democratização como uma possibilidade, um processo, um movimento da realidade concreta que possibilita um caminhar para a democracia. Democratização, portanto, é busca, é anseio, é perspectiva, é trajetória, é construção, é o fazer levando em conta o aqui-agora (com suas inconsistências, com suas perturbações). Numa síntese simplificada, poderíamos dizer: democratização é caminhar na direção da democracia, ou seja, tendo essa como referência. Portanto, salientamos que a democratização do acesso a universidade exige melhor reflexão quanto ao seu papel na sociedade, pois, se constitui um importante caminho para o avanço nas políticas educacionais.

\section{O meio social do estudante: contribuições de Pierre Bourdieu}

A partir das contribuições teóricas de Pierre Bourdieu, percebemos que o meio social dos estudantes pode influenciar o desempenho escolar, pois este está relacionado com a origem e com uma bagagem socialmente construída. Nesse sentido, trouxemos para a discussão da permanência universitária, de forma geral neste projeto, os conceitos de campo, capital cultural, ethos e habitus. Essas contribuições teóricas são relevantes à análise do estudo por desmistificar a ideologia do dom e da meritocracia sobre o desempenho escolar.

$\mathrm{O}$ ingresso de indivíduos de camadas populares nas universidades públicas não é suficiente para fazê-los pertencentes ao campo científico e não ocorre de uma forma simples. Segundo Bourdieu, a universidade é um campo de produção de conhecimento, um espaço de relações em que a luta que se trava é em busca da autoridade (ou de competência) científica. Como explica Bourdieu (1983, p. 122):

O campo científico, enquanto sistema de relações objetivas entre posições adquiridas (em lutas anteriores) é o lugar, o espaço de jogo de uma luta concorrencial. O que está em jogo especificamente nessa luta é o monopólio da autoridade científica definida, de maneira inseparável, como capacidade técnica e poder social; ou, se quisermos, o monopólio da competência científica, compreendida enquanto capacidade de falar e agir 
legitimamente (isto é, de maneira autorizada e com autoridade), que é socialmente outorgada a um agente determinado.

Como a priori os estudantes que entram nas universidades não detêm capital científico, o capital cultural e o ethos podem fazer a diferença no campo. O capital cultural é a bagagem de cultura transmitida principalmente pela família, mas também recebe influências ao longo da educação básica, das viagens e dos cursos realizados. Dessa forma, os discentes chegam ao ensino superior com um capital cultural que é usado para diferenciá-los e hierarquizá-los segundo o bem cultural que esses estudantes produzem, apreciam e consomem (NOGUEIRA; NOGUEIRA, 2004).

O capital cultural é um conceito importante para compreendermos as desigualdades culturais, pois para Bourdieu (2012) a renda não é o fator determinante para o bom desempenho escolar. A bagagem de cultura construída, principalmente pelo meio familiar, e as atitudes e posturas em relação aos estudos é o que coloca o agente mais próximo ou distante do meio acadêmico.

Contudo, é comum encontrarmos baixa escolarização nas camadas populares, o que influencia as trajetórias escolares de seus membros, conforme podemos verificar no estudo de Silva et al (2018), em que analisam a composição do perfil do estudante, presente nos dados divulgados do Fórum Nacional dos Pró-Reitores de Assuntos studantis (FONAPRACE) ${ }^{3}$, coletados no ano de 2014 e produzidos e publicados no ano de 2016 :

\begin{abstract}
Estamos observando, por exemplo, que a baixa renda o caracteriza predominantemente, o que remete às condições objetivas para que desenvolvam os estudos de forma satisfatória. E, nesse bojo, podemos listar o tempo para o estudo, a aquisição de material (livros, equipamentos eletrônicos, jaleco, fotocópias etc.), o transporte utilizado, a participação em eventos (em geral pagos), entre tantos outros elementos que envolvem a condição das pessoas de baixa renda perante os desafios acadêmicos. (SILVA, et al, 2018, p. 123-124).
\end{abstract}

Para ajudar a compreender o processo de inserção do estudante na universidade pública, recorremos aos apontamentos de Bourdieu e Passeron (1975) que esclarecem, que no interior da instituição escolar se exige não apenas o conteúdo escolar, mas um habitus escolar. Os comportamentos e a

3 O Fonaprace reúne pró-reitores, decanos e responsáveis por assuntos comunitários e estudantil das instituições de ensino superior públicas do Brasil e se vincula à Associação Nacional dos Dirigentes das Instituições Federais de Ensino Superior (ANDIFES, 2016). 
forma com que os estudantes se relacionam com os conteúdos e com a cultura acadêmica precisa estar de acordo com a forma legitimada pelo campo científico, inculcando-lhes um novo habitus. É possível perceber com a análise dos autores a influência da família e da origem sobre o desempenho acadêmico dos estudantes, pois os filhos de pais graduados já detêm o habitus esperado pelo campo científico, facilitando a fruição no ensino superior e possibilitando a desigualdade de êxito, como destacado por Nogueira e Nogueira (2015) ao se referirem aos estudos de Bourdieu e Passeron:

[...] a escola não apenas valoriza a posse da cultura dominante, mas valoriza ainda uma certa forma de se relacionar com ela (marcada pela espontaneidade, desenvoltura, naturalidade), forma que é típica daqueles que a adquiriram precocemente, em seu meio social de origem, e inexistente entre aqueles que a receberam tardiamente e por meio de processos formais de aprendizagem (NOGUEIRA; NOGUEIRA, 2015, p. 53).

Consideramos que os estudos de Bourdieu demonstram que as dificuldades nos conteúdos escolares que muitos estudantes vivenciam não estão relacionadas ao dom, aptidão ou inteligência, mas a fatores externos aos alunos que influenciam suas trajetórias acadêmicas. As dificuldades sentidas são elementos que interferem na permanência desses estudantes na universidade.

\section{Percurso metodológico}

Intentando compreender as discussões que relacionam o ensino médio e a universidade, buscamos na pesquisa qualitativa os fundamentos necessários para o desenvolvimento do estudo. Assim, nosso estudo trata-se de uma pesquisa bibliográfica, baseando-se na modalidade de pesquisa conhecida como balanço de produção, que, pode ser definida como inventariar e sistematizar a produção de determinada área do conhecimento, e apesar de tal prática ainda ser recente no Brasil é de grande importância para subsidiar a compreensão do estado alcançando pelo conhecimento a respeito de determinado tema, sua amplitude, tendências teóricas e vertentes metodológicas. (FREITAS et al, 2015).

Para o levantamento da produção acadêmica acerca do objeto deste estudo, recorreu-se às seguintes bases de dados: Portal de teses e dissertações da CAPES/MEC; Portal de Periódicos da CAPES/MEC; na base de pesquisa do Scientific Electronic Library Online (SciELO); Portal brasileiro de publicações científicas em acesso aberto (Oasisbr); e no Domínio Público. 
Destacamos que os levantamentos foram realizados no 1 ㅇ semestre de 2019 (considerando 20 de janeiro a 20 de julho de 2019), assim estudos lançados, posterior a esse período, não serão encontrados neste levantamento. Para delimitação do campo de busca, realizamos o mapeamento com as seguintes palavras-chave: Ensino médio e universidade; Relação ensino médio e universidade; Adaptação na universidade; Interface entre ensino médio e universidade.

O levantamento se construiu em três etapas:

- 1 a etapa - O Levantamento: a partir da palavra-chave previamente escolhida buscamos pelos níveis de Mestrado e Doutorado com pesquisas na área de Educação. Na busca dos artigos em periódicos, também focalizamos a área da educação. Essa etapa se deu exclusivamente pela leitura dos títulos;

- 2a etapa - A leitura dos Resumos e busca pelas pesquisas em Completo: procuramos nas leituras dos resumos identificar o foco de interesse de pesquisa, e aquelas que mais se aproximaram das nossas palavras-chave separamos em um quadro, para depois levantarmos os textos completos.

- 3a etapa - Leitura completa das pesquisas: nesta etapa partimos para a apreensão geral de cada pesquisa. Inicialmente procuramos ler a introdução de cada trabalho, por entendermos ser um tópico do trabalho que evidencia de maneira geral a proposta da pesquisa, seus objetivos, problemas, metodologias e breves considerações. Sequencialmente, procuramos em cada pesquisa apreender o que traziam a respeito da temática estudada.

\section{Resultados e discussão}

\section{A relação ensino médio e universidade nas produções acadêmicas}

O olhar para as produções acadêmicas nos permite compreender as definições conceituais, e levantamentos de dados da realidade que proporcionam analisar a relação ensino médio e universidade, e por quais caminhos isso vem acontecendo.

O Gráfico 1 ilustra o quantitativo de produções encontradas e que estão relacionadas a temática central: Ensino Médio e Universidade. 
Gráfico 1. Quantidade de produções encontradas que focalizam a relação ensino médio e universidade.

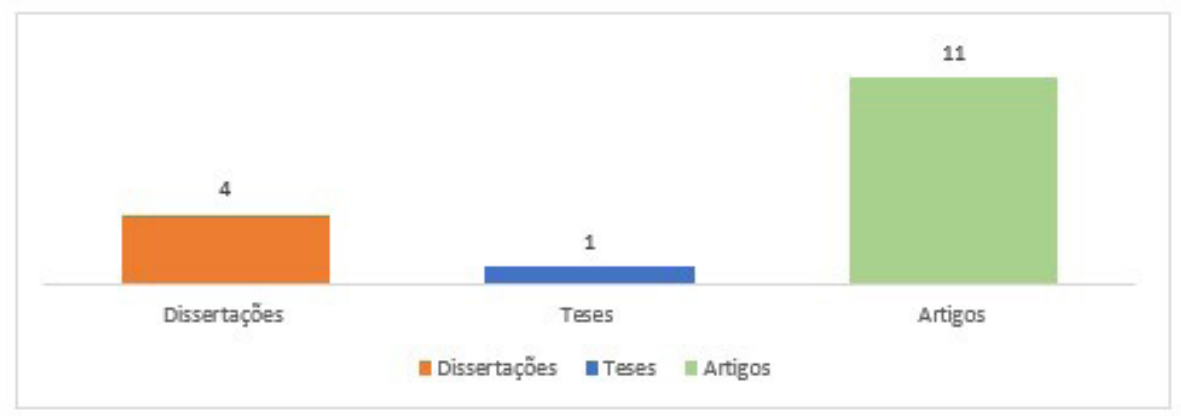

Fonte: SciELO, Oasisbr, CAPES/MEC e Domínio Público. 2019.

Feita a análise das produções acadêmicas, o Quadro 1 explicita os títulos selecionados e objetivos da pesquisa.

Quadro 1. Estudos com a temática ensino médio e universidade.

\begin{tabular}{|c|c|c|}
\hline Título do trabalho & Objetivo & Ano \\
\hline $\begin{array}{lrr}\text { Juventudes } & \text { e Ensino } \\
\text { Médio: } & \text { transições, } \\
\text { trajetórias e projetos } \\
\text { de futuro. } \\
\text { Doutorado]. }\end{array}$ & $\begin{array}{l}\text { Esta investigação intenta captar os sentidos } \\
\text { atribuídos pelos jovens às transições } \\
\text { experimentadas no ensino médio visando } \\
\text { compreender a relação existente entre esse nível } \\
\text { de ensino e seus projetos de futuro. }\end{array}$ & 2016. \\
\hline $\begin{array}{l}\text { Estratégias estudantis } \\
\text { para alcançar o ensino } \\
\text { superior: o caso do } \\
\text { IFBA. [Dissertação de } \\
\text { Mestrado]. }\end{array}$ & $\begin{array}{l}\text { O principal objetivo da investigação é identificar as } \\
\text { estratégias escolares que os estudantes dos cursos } \\
\text { técnicos integrados ao ensino médio constroem } \\
\text { para chegar ao ensino superior. }\end{array}$ & 2014. \\
\hline $\begin{array}{l}\text { Da transição à } \\
\text { permanência no ensino } \\
\text { médio: o papel da } \\
\text { família na trajetória do } \\
\text { aluno ao longo da última } \\
\text { etapa da educação } \\
\text { básica. [Dissertação de } \\
\text { Mestrado]. }\end{array}$ & $\begin{array}{l}\text { Esse trabalho se propões a investigar qual o papel } \\
\text { da família no processo de transição e permanência } \\
\text { no ensino médio. }\end{array}$ & 2015. \\
\hline
\end{tabular}




\begin{tabular}{|c|c|c|}
\hline $\begin{array}{l}\text { Modelo psicológico, } \\
\text { sociocultural } \\
\text { psicossocial } \\
\text { desempenho acadêmico } \\
\text { na transição do Ensino } \\
\text { Médio à Educação } \\
\text { Superior: o caso do } \\
\text { curso de Licenciatura } \\
\text { em Matemática da } \\
\text { UFTM. [Dissertação de } \\
\text { Mestrado]. }\end{array}$ & $\begin{array}{l}\text { O trabalho teve como objetivo propor um modelo } \\
\text { eclético (considerando aspectos psicológicos, } \\
\text { socioculturais e psicossociais), de avaliação do } \\
\text { desempenho acadêmico de alunos do curso de } \\
\text { Licenciatura em Matemática que transitam do } \\
\text { Ensino Médio para a Educação Superior a partir da } \\
\text { abordagem teórica das transições. }\end{array}$ & 2017. \\
\hline $\begin{array}{l}\text { Trajetórias de estudantes } \\
\text { da rede pública que } \\
\text { ingressam, permanecem } \\
\text { e obtém êxito numa } \\
\text { universidade pública. } \\
\text { [Dissertação } \\
\text { Mestrado]. }\end{array}$ & $\begin{array}{l}\text { Teve como objetivo investigar a trajetória de } \\
\text { estudantes da rede pública que ingressaram em } \\
\text { uma universidade pública. }\end{array}$ & 2012. \\
\hline $\begin{array}{l}\text { Transição e adaptação } \\
\text { à universidade: } \\
\text { apresentação de } \\
\text { um Questionário de } \\
\text { Vivências Acadêmicas } \\
\text { (QVA). [Artigo]. }\end{array}$ & $\begin{array}{l}\text { Este artigo analisa o processo de transição } \\
\text { e adaptação à universidade e apresenta o } \\
\text { Questionário de Vivências Acadêmicas. }\end{array}$ & 2000. \\
\hline $\begin{array}{l}\text { Desafios do ensino } \\
\text { superior para estudantes } \\
\text { de escola pública: } \\
\text { um estudo na UFLA. } \\
\text { Revista pensamento } \\
\text { contemporâneo em } \\
\text { administração. [Artigo]. }\end{array}$ & $\begin{array}{l}\text { Busca compreender os desafios enfrentados por } \\
\text { estudantes vindos de escolas públicas, por meio da } \\
\text { análise, em específico, do curso de Administração } \\
\text { da Universidade Federal de Lavras, entre } 2005 \text { a } \\
2010 \text {. }\end{array}$ & 2012. \\
\hline $\begin{array}{l}\text { Transição para o ensino } \\
\text { superior: aspiração } \\
\text { dos alunos do ensino } \\
\text { médio de uma escola } \\
\text { pública. [Artigo]. }\end{array}$ & $\begin{array}{l}\text { O trabalho discute resultados de uma pesquisa } \\
\text { que identifica e analisa projetos e aspirações } \\
\text { de continuidade dos estudos de alunos do } \\
\text { ensino médio de uma escola estadual da região } \\
\text { metropolitana de Belo Horizonte, Minas Gerais. }\end{array}$ & 2016. \\
\hline $\begin{array}{l}\text { A difícil transição: a } \\
\text { participação da família } \\
\text { na escolha profissional } \\
\text { de jovens egressos do } \\
\text { ensino médio. [Artigo]. }\end{array}$ & $\begin{array}{l}\text { Essa pesquisa discute como as diferentes gerações } \\
\text { presentes em um mesmo espaço doméstico } \\
\text { enfrentam o ingresso no mercado de trabalho, } \\
\text { como constroem suas estratégias e planos frente } \\
\text { ao futuro e como se relacionam com outras esferas } \\
\text { de socialização do jovem. }\end{array}$ & 2016. \\
\hline
\end{tabular}




\begin{tabular}{|c|c|c|}
\hline $\begin{array}{l}\text { O desempenho } \\
\text { acadêmico como } \\
\text { indicador de qualidade } \\
\text { da transição Ensino } \\
\text { M é d i o - E d u c a çã o } \\
\text { Superior. [Artigo]. }\end{array}$ & $\begin{array}{l}\text { Buscou-se conhecer fatores associados ao êxito na } \\
\text { transição Ensino Médio-Educação Superior. }\end{array}$ & 2014. \\
\hline $\begin{array}{l}\text { A experiência de afiliação } \\
\text { entre } \quad \text { estudantes } \\
\text { universitários de origem } \\
\text { popular: primeiros } \\
\text { achados. [Artigo]. }\end{array}$ & $\begin{array}{l}\text { O objetivo deste trabalho é apresentar os } \\
\text { primeiros resultados, análises e discussões acerca } \\
\text { da compreensão da experiência de afiliação entre } \\
\text { estudantes universitários de origem popular, na } \\
\text { Universidade Federal do Oeste da Bahia (UFOB). }\end{array}$ & 2018. \\
\hline $\begin{array}{l}\text { Ao final da educação } \\
\text { básica: o que pensam } \\
\text { jovens alunos sobre } \\
\text { suas escolarizações, } \\
\text { suas juventudes e seus } \\
\text { projetos. [Artigo]. }\end{array}$ & $\begin{array}{l}\text { No artigo se analisam resultados de duas pesquisas } \\
\text { que tiveram o/a jovem aluno/aluna como sujeito } \\
\text { privilegiado da investigação, através das suas } \\
\text { narrativas e representações sobre ser jovem, ser } \\
\text { aluno, ser jovem aluno, as vivência na escola e os } \\
\text { projetos a partir da escolarização. }\end{array}$ & 2012. \\
\hline $\begin{array}{l}\text { Transição do ensino } \\
\text { médio para a } \\
\text { universidade: um estudo } \\
\text { qualitativo sobre os } \\
\text { fatores que influenciam } \\
\text { este processo e suas } \\
\text { possíveis consequências } \\
\text { comportamentais. } \\
\text { [Artigo]. }\end{array}$ & $\begin{array}{l}\text { Teve como objetivo a análise dos fatores que } \\
\text { influenciaram na adaptação do aluno, egresso } \\
\text { do ensino médio, à vida universitária, bem como } \\
\text { a identificação das mudanças comportamentais } \\
\text { ocorridas em função desse processo de transição } \\
\text { acadêmica. }\end{array}$ & 2015. \\
\hline $\begin{array}{l}\text { O desenvolvimento de } \\
\text { uma escala de transição } \\
\text { e adaptação acadêmica. } \\
\text { [Artigo]. }\end{array}$ & $\begin{array}{l}\text { O objetivo deste estudo foi desenvolver um } \\
\text { instrumento que avalie a experiência de transição } \\
\text { acadêmica enfrentada por jovens calouros. }\end{array}$ & 2016. \\
\hline $\begin{array}{l}\text { Entre a escola pública } \\
\text { e a universidade: longa } \\
\text { travessia para jovens de } \\
\text { origem popular [e-book } \\
\text { scielo] }\end{array}$ & $\begin{array}{l}\text { Refletir sobre o caminho percorrido entre o ensino } \\
\text { médio e o ensino superior, entre o curso médio na } \\
\text { escola pública, o vestibular e a universidade. }\end{array}$ & 2011. \\
\hline $\begin{array}{l}\text { Expectativas de jovens do } \\
\text { ensino médio público em } \\
\text { relação ao estudo e ao } \\
\text { trabalho. [Artigo]. }\end{array}$ & $\begin{array}{l}\text { O artigo analisa as expectativas de jovens do } \\
\text { ensino médio de escolas públicas em relação à } \\
\text { continuidade dos estudos e à inserção no mercado } \\
\text { de trabalho. }\end{array}$ & 2015. \\
\hline
\end{tabular}

Fonte: SciELO, Oasisbr, CAPES/MEC e Domínio Público. 2019.

Desse modo, a partir dessas pesquisas podemos constatar que a transição do ensino médio para a universidade se dispõe de diferentes fatores o 
qual contribui ou desestimula o estudante a seguir estudando após o termino dessa trajetória, como podemos evidenciar no artigo de Coutrim, Cunha e Matos sobre a difícil transição e a participação da família:

Ao terminar o Ensino Médio, os jovens encontram- se sob um turbilhão de informações, pressões, descobertas e frustrações, e é justamente nesse contexto que eles são levados a fazer suas escolhas profissionais em um cenário mais ou menos conhecido (ou percebido) por eles, que é o exigente mercado de trabalho. (COUTRIM; CUNHA; MATOS, 2016, p. 175).

Assim, podemos entender que nessa fase final da educação básica os jovens estudantes se encontram em dificuldades para decidir o que farão no futuro tão próximo, como por exemplo, a escolha pelo mercado de trabalho ou pelo ingresso na universidade e, sobe essa escolha é importante à ajuda da família. Podemos ver esse conflito também nos escritos de Sant'ana sobre a permanência no ensino médio, a seguir:

O ambiente familiar é de extrema importância na medida em que os pais podem orientar seus filhos sobre os benefícios de se concluir os estudos e auxiliar no processo de aprendizado dos mesmos, fornecendo ambiente, propício ao desenvolvimento intelectual. (SANT'ANA, 2015, p. 52)

Desse modo, na análise de Sant'ana, a ajuda familiar é importante na trajetória escolar, pois fornecerão incentivos e atenção para o filho, e auxiliarão na escolha intelectual de ir para uma universidade. Ainda sobre trajetória escolar e as estratégias criadas para alcançar a educação superior, verificamos na pesquisa de Oliveira (2014):

As trajetórias escolares dos estudantes participantes revelam uma preocupação das famílias desde cedo com as questões ligadas aos saberes escolares e também sobre a importância da escola como um meio para se obter uma vida melhor. Cada jovem demonstra que sua chegada ao Instituto Federal foi permeada por relações parentais de incentivo e apoio e, somente a partir desse auxílio, cada um conseguiu estabelecer uma relação com o mundo escolarizado. (OLIVEIRA, 2014, p. 150).

Assim, percebe-se que os incentivos e apoio de seus familiares os instigou a avançar nas questões escolares, com vistas a obter uma vida melhor, 
esse papel dentro das famílias torna a escolha pelo ingresso na universidade menos preocupante. Entretanto, diferentemente desse cenário, nas escolares regulares observamos que muitos dos estudantes pesquisados não têm esperanças de poder ingressar na universidade. São notórias as dificuldades enfrentadas para esse acesso, principalmente para estudantes de escolas públicas e de baixa renda, como podemos observar no artigo de Oliveira e Silva:

Ingressar em um curso universitário é sonho de milhares de estudantes. Os estudantes de origem popular, desde muito cedo sofrem com a pouca qualidade do ensino oferecido na maioria das escolas públicas. A lacuna da escolarização básica se mostra como um obstáculo para acesso à universidade, haja vista a enorme competitividade dos processos seletivos. (OLIVEIRA; SILVA, 2018, p. 10)

Em vista disso, é possível interpretar que não basta apenas a ajuda da família, os meios também precisam favorecer esse ingresso à universidade, mesmo vislumbrando um futuro em uma faculdade, os estudantes oriundos de escola pública, encontram-se com maiores dificuldades para vencer os processos seletivos. Podemos encontrar consonância nos escritos de Penatieri, Falcão e Martínez, que tratam sobre o que os jovens pensam sobre sua escolarização:

Ser jovem, de classe social baixa ou média baixa e estar concluindo a educação básica traz uma configuração de diversos modos de viver os tempos sociais produzidos em torno da vida escolar, tensão não resolvida entre as demandas do presente e a "recompensa", perspectivas incertas do/no futuro, dadas as restritas chances de continuidade de estudos no ensino superior e as crescentes dificuldades de inserção no mundo do trabalho que emprega cada vez menos e exige cada vez mais qualificação. (PENATIERI, FALCÃO, MARTÍNEZ, 2012, p. 127).

Assim, as tensões sobre os estudantes que concluem o ensino médio estão ligadas às incertezas e medos, tendo em vista, que não sabem se conseguirão ingressar na universidade ou se alcançarão um emprego. E mesmo nessa relação, os estudantes são esperançosos quanto ao ingresso à universidade, podemos ver essas expectativas pelo artigo de Vasquez e Souza sobre os jovens do ensino médio público em relação ao estudo e ao trabalho:

Nossa argumentação até aqui demonstra que os jovens têm em seu horizonte a continuidade dos estudos (pretendem ingressar 
na universidade), reconhecem dificuldades para a continuidade dos estudos (principalmente a necessidade de trabalhar), mas não se resignam à exclusão: avaliam que as políticas de acesso ao ensino superior aumentaram suas chances (especialmente o ENEM e as cotas, para os jovens autodeclarados negros) e procuram montar uma estratégia para driblar as dificuldades que esperam encontrar. (VASQUEZ; SOUZA, 2015, p. 420).

Desse modo, conseguimos destacar que os jovens que concluem o ensino básico têm perspectivas de ingressar na universidade com base nas políticas de acesso. Contudo, avaliando o acervo da pesquisa, observamos que mesmo tendo a conquista de ingressar no ensino superior, o estudante de renda baixa advindo de escola pública precisa encarar diferentes dificuldades para permanecer estudando, Alvarenga et al (2012) explicita esses problemas a seguir:

\begin{abstract}
Desta forma, apenas garantindo que estudantes de escola pública, em virtude do aumento no número de vagas, consigam se inserir dentro de uma universidade pública, não representa, por si só, uma forma de democratização do ensino superior, haja vista as dificuldades que ainda poderão permear seu processo de graduação. Tendo em vista o déficit educacional deste estudante em detrimento aos demais, este pode apresentar maior dificuldade com os conteúdos, ter que estudar mais para obter resultado semelhante ao de outros colegas, pode precisar da ajuda de monitorias ou aulas particulares para suprir suas deficiências, pode ser excluído de atividades extracurriculares, dentre outros desafios. (ALVARENGA ET AL, 2012, p. 62).
\end{abstract}

Assim, nessa fase de transição, ingresso e permanência, os estudantes provenientes de escola pública perpassam por diferentes desafios, tendo em vista que há uma lacuna no capital cultural desses alunos. Quando a família tem maiores acessos à cultura, maiores são também as probabilidades de os estudantes ingressarem e permanecerem na instituição escolhida. Observemos no artigo de Braga e Xavier sobre a transição para o ensino superior:

Alunos cujas famílias possuem capital cultural e renda mais elevados, cujos pais podem ajudá-los economicamente a cursar a universidade, que consideram importante cursar a universidade, alunos que estudaram integralmente ou parte do ensino fundamental na rede privada, que nunca foram reprovados, que seus colegas pretendem ingressar no ensino superior e que 
têm professores que os incentivam a fazer um curso superior, as meninas e os brancos são aqueles alunos mais prováveis de terem aspirações de continuidade de estudos após o ensino médio. (BRAGA; XAVIER, 2016, p. 254).

Uma das estratégias de ajudar o aluno a permanecer nas instituições de ensino são as políticas de permanência da educação superior. É notória na dissertação de Silva a relação dos alunos com essas políticas e como alguns conseguiram permanecer, vencendo as dificuldades que lhes eram impostas:

A opção de estágio remunerado através de bolsa em projetos de extensão, bases de pesquisa ou monitoria foram evidenciados em várias falas. O estudante de matemática da UFRN, que não conseguiu conciliar o emprego que tinha antes de ingressar na universidade, encontrou na monitoria o caminho para ter uma ajuda financeira [...]. (SILVA, 2012, p. 105).

Mas, além disso, os estudantes provenientes de classe popular e de escola pública têm que lidar com as desigualdades socioeducacionais, e os estereótipos que os fazem se sentir incapacitados a continuar sua formação pós-ensino básico. Sampaio elucida essa questão:

Se o ensino médio é uma experiência complexa para qualquer jovem, dado que coincide com um período de transições, em várias dimensões individuais e sociais, ele parece ser mais difícil para esses jovens, desafiados a enfrentar as várias lógicas de exclusão e, por que não dizer, o estereótipo de estudante de escola pública, ou seja, aquele que não domina inteiramente conhecimentos básicos e que deve, portanto, se desdobrar para superar as fragilidades e lacunas existentes em sua formação escolar. (SAMPAIO, 2011, p. 38 - 39).

Nessa perspectiva, os estudantes preferem abrir mão do ensino superior para concorrer uma vaga no mercado de trabalho, que por vezes não conseguem alcançar também. É importante a intervenção da escola nessa relação, estimular os alunos a cursar o ensino superior e/ou integrar a relação entre universidade e trabalho. Como Pinho et al destacam:

É importante ressaltar também o papel da escola do ensino médio na adaptação acadêmica universitária. Por exemplo, as escolas que promovem atividades vocacionais e outras atividades com o objetivo de aproximar o estudante ao contexto uni- 
versitário geralmente contribuem, futuramente, na adaptação do estudante ao ensino superior. (PINHO ET AL, 2016, P. 52).

É importante esse destaque e ajuda da escola nas decisões futuras de seus estudantes. Essa formação e informação recebida dos alunos no ensino médio poderão ajudá-los a alcançar êxito na universidade, conforme Fagundes et al (2014), explanam em seu artigo a seguir:

A formação recebida no Ensino Médio se constitui em uma base, tanto teórica como procedimental e atitudinal, que permite aos alunos lidar com a sua integração na Educação Superior. (FAGUNDES ET AL, 2014, p. 655).

Encontramos consonância em escrito de Silva em sua dissertação sobre o desempenho acadêmico:

Além destes fatores, esta etapa é obrigatória na formação que
antecede a entrada na Educação Superior, e nela deve-se esti-
mular a iniciativa dos estudantes, utilizando metodologias de
ensino e de avaliação que possibilitem ao aluno enxergar futuras
oportunidades na continuação dos estudos. (SILVA, 2017, p.7).

Contudo, é importante destacar que essa fase da juventude e ingresso na universidade sofre muitos e diferentes processos, assim, Almeida et al (2015, p. 190) retrata que isso precisa ser "conceitualizado como um processo complexo e multidimensional", que relaciona vários fatores na vida do estudante.

Em pesquisa nessa temática, observamos também que os estudantes de ensino profissional, acreditam ter mais facilidade para ingressar ao ensino superior ou concorrer ao mercado de trabalho que um estudante de ensino regular, Alves destaca em sua Tese essa estratégia:

A possibilidade de cursar o ensino médio profissionalizante em uma escola que ofereça um curso técnico atrelado a uma base curricular comum aparece na fala da jovem como uma "vantagem" em relação aos alunos que estão no ensino médio regular. E embora atribua maior importância à dimensão do estudo não descarta a possibilidade, caso surjam oportunidades, de conciliação entre escola e trabalho num plano futuro. (ALVES, 2016, p.55). 
Por fim, nesse trabalho devemos destacar que os fatores elencados em cada pesquisa contribuíram para compreendermos melhor essa fase de transição para o estudante, conforme ressalta Pinho et al (2015):

As grandes diferenças apontadas entre o ensino médio e a universidade ajudam a entender por que este processo é tão complexo e capaz de mobilizar o estudante ingressante. (PINHO ET AL, 2015, p.42).

Os diversos fatores de ingresso e permanência que envolve essa transição dos alunos ao ensino superior, estão intimamente atrelados com as relações, apoio e escolhas que os estudantes tomam ao findar o ensino básico. É notório que para alguns, essas dificuldades são maiores do que para outros, e para isso precisamos discutir e ampliar ainda mais a democratização e as políticas de permanência nas universidades.

\section{Considerações Finais}

Concluímos que o movimento de pesquisa que busca compreender a relação ensino médio e universidade ainda está em construção. Ao refletirmos na implantação das políticas de ação afirmativa na educação superior, compreendemos que estudos precisam ser fomentados, para demonstrar os desafios da realidade concreta e de possíveis mudanças sociais.

Ainda são muitos os desafios no caminho entre o ensino médio e a universidade, principalmente no que concerne ao ensino público. Nas pesquisas levantadas é possível verificar que jovens optam em inserir-se ao mercado de trabalho e deixar o sonho de ingresso na universidade para o futuro, demonstrando assim, que as necessidades econômicas e de sobrevivência, se sobrepõe a possibilidade de continuar a estudar. E é nesta realidade que as políticas de permanência se fazem imprescindíveis, pois permitem que este grupo social, que tem pouco acesso ao capital econômico, ingresse e permaneça na universidade.

O texto ensaiou o debate da relação entre ensino médio e universidade e sua possível interface com as ações de permanência. O intento foi trazer à tona elementos conceituais e de pesquisas já realizados no âmbito acadêmico visando à continuidade nos estudos, e destacar a necessidade de mais aprofundamentos teóricos que devem reverberar em práticas que aproximem a universidade do ensino médio. 


\section{Referências}

ANDIFES. Associação Nacional dos Dirigentes das Instituições Federais de Ensino Superior. FONAPRACE - Fórum Nacional de Pró-Reitores de Assuntos Comunitários e Estudantis. IV Pesquisa do Perfil Socioeconômico e Cultural dos Estudantes de Graduação das Instituições Federais de Ensino Superior Brasileiras. Uberlândia, 2016.

ALMEIDA, Leandro S.; SOARES, Ana Paula C.; FERREIRA, Joaquim Armando G. Transição e adaptação à Universidade: Apresentação de um Questionário de Vivências Académicas (QVA). Psicologia, Lisboa, v. 14, n. 2, p. 189-208, jul. 2000. Disponível em <http://www.scielo.mec.pt/scielo.php?script=sci_arttext\&pid=S0874-20492000000200005\&lng=pt\&nrm=iso>. Acesso em: 20 de jan. 2019.

ALVARENGA, Carolina Faria; SALES, Aline Pereira; COSTA, Adriano Dias da; COSTA, Maurício Donizete da. VERONEZE, Ricardo Braga; SANTOS, Thiago Lima Bahia. Desafios do ensino superior para estudantes de escola pública: um estudo na UFLA. Revista pensamento contemporâneo em administração. Rio de Janeiro, v. 6, n. 1 jan./mar. 2012. p. 55-71.

ALVES, Maria Alda de Sousa. Juventudes e Ensino Médio: transições, trajetórias e projetos de futuro. Tese (doutorado). Universidade Federal do Ceará, Centro de Humanidades, Programa de Pós-Graduação em Sociologia. Fortaleza, 2016. Disponível em: http://www.dae.ufla.br/pet/wp-content/ uploads/2017/03/2011_ENGRP_OS-DESAFIOS-DO-ENSINO-SUPERIOR-1.pdf Acesso em: 20 de jan. $2 \overline{0} 19$.

BOURDIEU, Pierre; PASSERON, Jean Claude. A reprodução: elementos para uma teoria do sistema de ensino. Rio de Janeiro: Livraria Francisco Alves Editora, 1975.

BOURDIEU,Pierre. O campo científico. In: ORTIZ, Renato (Org.). Pierre Bourdieu. Sociologia. São Paulo: Ática, 1983.

BRAGA, Maria José and XAVIER, Flavia Pereira. Transição para o ensino superior: aspiração dos alunos do ensino médio de uma escola pública. Educar em Revista, Curitiba, Brasil, n. 62, out./dez. 2016. p. 245-259. Disponível em: https://www.scielo.br/pdf/er/n62/1984-0411-er-62-00245.pdf Acesso em: 22 de jan. 2019.

COUTRIM, Rosa Maria da Exaltação; CUNHA, Maria Amália de Almeida ; MATOS, Daniel Abud Seabra. A difícil transição: a participação da família na escoIha profissional de jovens egressos do ensino médio. Revista da FAEEBA - Educação e Contemporaneidade, Salvador, v. 25, n. 47, p. 173-186, set./dez. 2016. 
Disponível em: https://www.repositorio.ufop.br/handle/123456789/9510 Acesso em: 22 de jan. 2019.

CURY, Carlos R. Jamil. Educação e contradição. 6. ed. São Paulo: Cortez, 1986.

FAGUNDES, Caterine Vila; LUCE, Maria Beatriz and RODRIGUEZ ESPINAR, Sebastián. $O$ desempenho acadêmico como indicador de qualidade da transição Ensino Médio-Educação Superior. Ensaio: aval. pol. públ. Educ. Rio de Janeiro, 2014, vol.22, n.84, p.635-669. Disponível em: https://www.scielo. br/scielo.php?pid=S0104-40362014000300004\&script=sci_abstract\&tlng=pt Acesso em: 15 de abr. 2019.

NOGUEIRA, Maria Alice; NOGUEIRA, Cláudio M. Martins. Bourdieu \& a educação. 2.ed. Belo Horizonte, Autêntica, 2004.

NOGUEIRA, Maria Alice. NOGUEIRA, Cláudio M. Os herdeiros: fundamentos para uma sociologia do ensino superior. Educação e Sociedade, Campinas, v. 36, no. 130, p. 47-62, jan./mar., 2015.

OLIVEIRA, G. M. B.; SILVA, R. M. A experiência de afiliação entre estudantes universitários de origem popular: primeiros achados. In: SEMINÁRIO NACIONAL DE SOCIOLOGIA DA UFS, 2., 2018, São Cristóvão, SE. Anais [...]. São Cristóvão, SE: PPGS/UFS, 2018. Disponível em: https://ri.ufs.br/handle/riufs/13005 Acesso em: 10 de maio 2019.

OLIVEIRA, Alcione Silva de Oliveira e. Estratégias estudantis para alcançar o ensino superior: o caso do IFBA. Dissertação (mestrado). Universidade Federal da Bahia, Instituto de Humanidades, Artes e Ciências, 2014. Disponível em: https://repositorio.ufba.br/ri/handle/ri/15608 Acesso em: 22 de jan. 2019.

FREITAS, A. V.; PALANCH, W. B. DE L. Estado da Arte Como Metodologia de Trabalho Científico na Área de Educação Matemática: Possibilidades e Limitações. Perspectivas da Educação Matemática, v. 8, n. 18, 18 dez. 2015.

PENATIERI, Gisele Rogéria; FALCÃO, Christiane Rodrigues; MARTínEZ, Silvia Alicia. Ao final da educação básica: o que pensam jovens alunos sobre suas escolarizações, suas juventudes e seus projetos. Educação foco, Juiz de Fora, v. 16, n. 2, p. 117-139, set 2011/fev 2012.

PINHO, Ana Paula Moreno; DOURADO, Laís Carvalho; AURÉLIO, Rebeca Martins; BASTOS, Antonio Virgílio Bittencourt. Transição do ensino médio para a universidade: um estudo qualitativo sobre os fatores que influenciam este processo e suas possíveis consequências comportamentais. Revista de Psicologia, Fortaleza, v. 6 n. 1, p. 33-47, jan./jun. 2015. 
PINHO, Ana Paula Moreno; TUPINAMBÁ, Antonio Caubi Ribeiro; BASTOS, Antonio Virgílio Bittencourt. $O$ desenvolvimento de uma escala de transição $e$ adaptação acadêmica. Revista de Psicologia, Fortaleza, v. 7 n. 1, p. 51-64, jan./jun. 2016.

SAMPAIO, SMR. (Org). Entre a escola pública e a universidade: longa travessia para jovens de origem popular. In: Observatório da vida estudantil: primeiros estudos. Salvador: EDUFBA, 2011, pp. 27-51. ISBN 978-85-232-1211-7. Disponível em: <http://books.scielo.org>. Acesso em: 09 de abr. 2019.

SANT'ANNA, Elder Generozo. Da transição à permanência no ensino médio: o papel da família na trajetória do aluno ao longo da última etapa da educação básica. Dissertação (Mestrado em Educação). Universidade de São Paulo. Ribeirão Preto, 2015.

SILVA, Maria Das Graças Martins da; LUZ, Jackeline Nascimento Noronha da; NOGUEIRA, Patrícia Simone. Formação e perfil estudantil: aproximações com vistas à permanência do estudante. Movimento-Revista de Educação, Niterói, ano 5, n.9, p.107-130, jul./dez. 2018.

SILVA, Maria das Graças Martins da. VELOSO, Tereza Christina Mertens Aguiar. Democratização do ingresso na educação superior: liames com a teoria marxista. Linhas Críticas, Brasília, DF, v.19, n.39, p. 409-428, mai./ago.2013.

SILVA, Henrique Grabalos. Modelo psicológico, sociocultural e psicossocial do desempenho acadêmico na transição do Ensino Médio à Educação Superior: o caso do curso de Licenciatura em Matemática da UFTM. Dissertação (Mestrado em Educação). Universidade Federal do Triângulo Mineiro. Uberaba, MG, 2017.

SILVA, SILCIA SOARES FARIAS. Trajetórias de estudantes da rede pública que ingressam, permanecem e obtém êxito numa universidade pública. Dissertação (mestrado). Programa de Pós-Graduação em Educação. Universidade Federal do Rio Grande do Norte, Natal, 2012.

VASQUEZ, Daniel Arias; SOUZA, Davisson Charles Cangussu. Expectativas de jovens do ensino médio público em relação ao estudo e ao trabalho. Educação e Pesquisa, São Paulo, v. 41, n. 02, p. 409-426, abr./jun. 2015. 